\title{
Abacavir Sulfate/Lamivudine
}

National Cancer Institute

\section{Source}

National Cancer Institute. Abacavir Sulfate/Lamivudine. NCI Thesaurus. Code C157405.

A fixed combination of abacavir sulfate, a nucleoside reverse transcriptase inhibitor

(NRTI) analog of guanosine and lamivudine, an NRTI analog of cytidine, that is used to treat human immunodeficiency virus (HIV) infection. Upon oral administration, abacavir and lamivudine are phosphorylated into active metabolites that compete for incorporation into viral DNA. These metabolites inhibit the HIV reverse transcriptase (RT) enzyme competitively and act as a chain terminator of DNA synthesis. This interferes with the generation of DNA copies of viral RNA, which is necessary for the synthesis of new virions. 